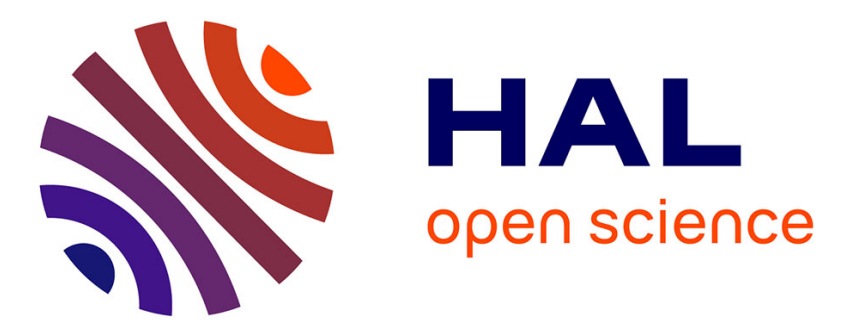

\title{
Estimation of salt mixture damage on built cultural heritage from environmental conditions using ECOS-RUNSALT model
}

Beatriz Menendez

\section{- To cite this version:}

Beatriz Menendez. Estimation of salt mixture damage on built cultural heritage from environmental conditions using ECOS-RUNSALT model. Journal of Cultural Heritage, 2017, 24, pp.22-30. 10.1016/j.culher.2016.11.006 . hal-03266049

\section{HAL Id: hal-03266049 \\ https://hal.science/hal-03266049}

Submitted on 30 Dec 2021

HAL is a multi-disciplinary open access archive for the deposit and dissemination of scientific research documents, whether they are published or not. The documents may come from teaching and research institutions in France or abroad, or from public or private research centers.
L'archive ouverte pluridisciplinaire HAL, est destinée au dépôt et à la diffusion de documents scientifiques de niveau recherche, publiés ou non, émanant des établissements d'enseignement et de recherche français ou étrangers, des laboratoires publics ou privés. 
Estimation of salt mixture damage on built cultural heritage from environmental conditions using ECOSRUNSALT model

\author{
Beatriz Menéndez \\ Geosciences et Environnement Cergy, University of Cergy-Pontoise, 5 mail Gay Lussac, 95031 Cergy-Pontoise \\ cedex, France
}

Tel +33 134257362. Beatriz.menendez@u-cergy.fr

\begin{abstract}
Salts are among the most active weathering agents acting in the degradation of cultural heritage, especially on stone and brick buildings. Most of the previous works on salt weathering studied only single salt composition despite the fact that in buildings a mixture of different salts is always present. This paper presents a methodology to estimate salt weathering from complex solution composition and meteorological data, temperature and relative humidity. The proposed method uses a thermodynamic model (ECOS-RUNSALT) to predict the variation of salt volume with changing environmental conditions. To illustrate how the developed method can be applied, two examples are presented. Firstly, the model has been applied to real measurements on a repairing mortar sample sampled from a building in the center of Paris. Secondly, the model has been applied to estimate salt damage produced by a theoretical salt composition in different locations of France. Possible applications in cultural heritage conservation are (i) the prediction of future behavior of cultural heritage building materials taking advantage of climatic models and (ii) a help to determine the optimal conditions to avoid, as much as possible, salt damage.
\end{abstract}

Keywords. Salt damage, stone, mortar, temperature, relative humidity

\title{
1. Research aims
}

This research deals with the prediction and quantification of weathering produced by complex salt mixtures as a function of the environmental conditions, temperature and relative humidity. Taking advantage of a thermodynamic salt equilibrium model developed by several European laboratories (University College London, the University of East Anglia Norwich and the University of Hamburg) and funded by the European Commission, the ECOS model, the final goal of the research is to develop a methodology to determine the temperature and relative humidity conditions where salt volume increase takes place during the precipitation of a complex brine.

\section{Introduction}

In temperate areas, salt crystallisation is one of the most important, if not the most important, factor in building and monumental stone weathering. The nature and origin of these salts are variable and have changed with time, mainly due to human activities in urban areas. When analysing weathered stone usually a combination of salts is found [1]. Goudie and Viles [2] established a review of the salts found in walls by different authors. The most frequent salts are gypsum with sodium sulphate, sodium chloride and sodium carbonate. Other salts found in buildings are sodium and potassium nitrates, sodium, magnesium and calcium carbonates, magnesium and calcium sulphates. The origin of these salts is also very different: air pollution (nitrogen oxides and sulphur dioxide), elements coming from building materials (stones, mortars, cements, metallic elements, etc.), and elements coming from groundwater. It is well know that the amount of sulphate supply to buildings decreases as sulphur amount in atmosphere has largely declined since the last century. However sulphur can remain within the stone for long periods and large amounts can still be found in building materials, thus having a predominant role on its deterioration [3]. 
Different approaches have been applied to study salt weathering on building materials. The most classical one consists in conducting experimental crystallization cycles on stone samples using a sodium sulphate solution. This kind of experiments started in $19^{\text {th }}$ century trying to simulate ice formation on building stones [4-5] and is the most common experience in laboratory studies. Another experimental approach is to study the behaviour of non-confined solutions exposed to changes in the environmental conditions [6] or to use artificial porous media to simulate salt crystallization processes in stones [7]. Some authors developed thermodynamic models to investigate the precipitation of salt crystals in confined and unconfined conditions. Such models allow to explain, for example, why salts with higher crystallization pressure induce less damage than others with lower crystallization pressure [8]. Benavente et al [9] proposed to use the "PHREEQC" model to predict not only which salt will precipitate from a predefined solution but also the induced crystallisation pressure. With this model it is possible to simulate the evolution of temperature and evaporation to simulate salt crystallization. Another thermodynamic model, ECOS (Environmental Control Of Salts), is able to describe the behavior of aqueous salt solutions, allowing the user to predict the equilibrium behavior of salt mixtures as a function of temperature and relative humidity. This model is the result of a collaboration between University College London (C. Price), the University of East Anglia Norwich (P. Brimblecombe, S. Clegg) and the University of Hamburg (M. Steiger) funded by the European Commission [10]. Bionda [11] developed a graphical user interphase for the ECOS model, RUNSALT.

Steiger and Heritage [12] pointed out the limits of this kind of thermodynamic models:

a) They are based on equilibrium conditions of the salt-water system and equilibrium pathways are predicted. However, in reality this is not necessarily the case. Metastable phases, that are less stable but form quickly, can be precipitated. The models do not take into account such precipitation processes which do not occur at saturation but at supersaturation conditions.

b) They neither consider that salt transitions are taking place in porous media where phenomena of fluid transport and fractionation are present, nor the behaviour of salt-water systems in pores.

c) The model predictions are accurate only if the salt mixture corresponds to the ions included in the model

It has been shown that the behaviour of salt mixtures is not a simple addition of those of simple individual salts [13-14]. Nevertheless in most of previous research works dealing with salt behaviour under changing meteorological or climatic condition, each salt is considered individually. There are a huge number of salt mixture compositions found in monuments and buildings, and it is not possible to simulate in laboratory experiments the behaviour of every salt mixture and to predict the respective crystallisation pathways [12].

When estimating the salt weathering evolution as a function of meteorological conditions, different criteria for individual salts have been used like for example, counting how many times relative humidity crosses the deliquescence limit of $\mathrm{NaCl}$ (from higher to lower) producing halite precipitation [15]. This methodology was applied in the Noah's Ark project to produce salt weathering maps for the 21th century. For sodium sulphate Benavente et al [16] propose an equation to determine when sodium sulphate precipitates inducing a crystallisation pressure higher than $10 \mathrm{MPa}$. Menendez [17] proposed a similar equation based on the transition conditions of the phase diagram for this salt. In this paper we consider not only the phase transitions but also precipitation/dissolution processes and the corresponding volume changes. It is recognized that there are other ageing factors associated with salt weathering: however as it is difficult to include all the weathering processes in a single model, we decided to focus here on salt volume changes only.

\section{Methodology}

In order to estimate salt weathering activity (past and future) as a function of environmental conditions (temperature and relative humidity) for salt mixtures, a new methodology taking into account the complex behaviour of solutions has been developed. The proposed methodology accounts for the effect of salt precipitation on building materials but does not consider other weathering processes such as freeze and thaw, grains thermal expansion, mineral dissolution, etc. Natural weathering processes are very complex and usually 
in models each weathering agent is considered independently. The ECOS-RUNSALT programme has been used to determine (i) the environmental conditions at which crystallization takes place and (ii) the nature of the salts that will crystallize. Salt crystallization at different temperature and relative humidity conditions has been modelled. In the ECOS-RUNASALT program, the inputs are the ionic composition $\left(\mathrm{Na}^{+}, \mathrm{K}^{+}, \mathrm{Mg}^{2+}, \mathrm{Ca}^{2+}, \mathrm{Cl}^{-}, \mathrm{NO}_{3}\right.$ and $\left.\mathrm{SO}_{4}{ }^{2-}\right)$ and the environmental conditions. The calculations can be done either at constant temperature (from $-30^{\circ} \mathrm{C}$ to $50^{\circ} \mathrm{C}$ ) and changing relative humidity (from $15 \%$ to $98 \%$ ), or at constant relative humidity and variable temperature, in the same range of values as for constant temperature calculations. The model provides results for the amount of precipitated salt as function of temperature (T) and relative humidity (HR).

To illustrate the proposed methodology, an example of initial ionic composition of the solution has been used. A reparation mortar sample $(0.1 \mathrm{~g})$ taken on the "Préfecture de Police" building in Paris has been placed in a container with distilled water $(10 \mathrm{~g})$ during $24 \mathrm{~h}$ after which the resulting solution was analysed using ion chromatography [18]. The results for the ions considered in the ECOS model can be seen in the first column of Table 1. For this ionic composition the charge balance is largely positive. Taking into account that $\mathrm{CO}_{3}{ }^{2-}$ is not considered in the programme, it has been assumed that some of $\mathrm{Ca}^{2+}$ ions come from carbonates and bicarbonates, and the ion composition has been corrected taking off excess of $\mathrm{Ca}^{+2}$ until the charge balance is 0 (second column of Table 1, Corrected $\mathrm{Ca}^{2+}$ ). For some complex composition including $\mathrm{Ca}^{2+}$ and $\mathrm{SO}_{4}{ }^{2-}$ ions, $\mathrm{ECOS}-$ RUNSAT cannot do the correct calculation and asks for removing Gypsum [19]. It was the case for the studied solution so that gypsum has been removed for a first calculation. The corrected ion composition after removing the total amount of $\mathrm{Ca}^{2+}$ and the corresponding $\mathrm{SO}_{4}{ }^{2-}$ to produce gypsum/anhydrite can be seen on the third column of Table 1 as well as the amounts removed. A second calculation was done with the removed amounts of $\mathrm{Ca}^{2+}$ and $\mathrm{SO}_{4}{ }^{2-}$ in order to obtain the volume of precipitated gypsum and anhydrite. Our final results are the combination of these two calculations.

Using the data from column 3 of Table 1, different simulations have been done at different temperatures from $0^{\circ} \mathrm{C}$ to $50^{\circ} \mathrm{C}$ with a $5^{\circ} \mathrm{C}$ step. For each temperature relative humidity varies from $15 \%$ to $98 \%$. As said before, in most of the cases ECOS-RUNSALT cannot do the calculation with gypsum, so two sets of calculations have been done: one without gypsum and one with the amount of $\mathrm{Ca}^{2+}$ and $\mathrm{SO}_{4}{ }^{2-}$ previously removed. Finally the results from both calculations have been added in order to obtain the total precipitate volume.

Figure 1 shows the evolution of salt composition obtained with ECOS-RUNSALT for 4 different temperatures $\left(0^{\circ} \mathrm{C}, 15^{\circ} \mathrm{C}, 30^{\circ} \mathrm{C}\right.$ and $\left.45^{\circ} \mathrm{C}\right)$ when varying relative humidity. The sum of the volumes of all the salts is presented as a double black line. It can be observed that at each temperature there are several relative humidity conditions where the volume of salt changes considerably. For example at $0^{\circ} \mathrm{C}$ the volume of most of the salt increases when relative humidity $(\mathrm{RH})$ increases from 45 to $50 \%$ and it decreases when $\mathrm{RH}$ increases from 65 to $70 \%$. We can consider that a decrease of RH from 70 to $65 \%$, produces an increase of the volume.

Looking at Figure 1 different steps can be analysed in detail taking into account that the maximum volume of salt found in our simulations is $130 \mathrm{~cm}^{3}$ that should be taken as reference:

At $0^{\circ} \mathrm{C}$ and for increasing $\mathrm{RH}$ :

a) At RH around $40 \%$, when $\mathrm{RH}$ increases, $\mathrm{MgSO}_{4} \cdot 4 \mathrm{H}_{2} \mathrm{O}$ changes into $\mathrm{MgSO}_{4} \cdot 6 \mathrm{H}_{2} \mathrm{O}$ and associated to this transformation $\mathrm{Mg}\left(\mathrm{NO}_{3}\right)_{2} \cdot 6 \mathrm{H}_{2} \mathrm{O}$ dissolves, $\mathrm{NaNO}_{3}$ slightly increases its volume and $\mathrm{NaCl}$ decreases its volume. The final result is a change of volume of around $60 \mathrm{~cm}^{3}$. This change is positive (volume increase) when $\mathrm{RH}$ increases but negative (volume reduction) when $\mathrm{RH}$ decreases.

b) At $\mathrm{RH} 45 \%, \mathrm{CaSO}_{4}$ transforms into $\mathrm{CaSO}_{4} \cdot 2 \mathrm{H}_{2} \mathrm{O}$ with a change of volume of $30 \mathrm{~cm}^{3}$, positive if $\mathrm{RH}$ increases but negative if $\mathrm{RH}$ decreases.

c) The most important volume changes take place when $\mathrm{RH}$ increases between $65 \%$ and $70 \%$. The progressive appearance of $\mathrm{Na}_{2} \mathrm{SO}_{4} \cdot 1 \mathrm{OH}_{2} \mathrm{O}$ is associated to the dissolution of $\mathrm{NaCl}, \mathrm{KNO}_{3}, \mathrm{NaNO}_{3}$ and $\mathrm{MgSO}_{4} \cdot 6 \mathrm{H}_{2} \mathrm{O}$. The total volume change is almost $50 \mathrm{~cm}^{3}$, negative when $\mathrm{RH}$ increases and positive when it decreases.

At $15^{\circ} \mathrm{C}$, when $\mathrm{RH}$ increases: 
a) At $\mathrm{RH}$ of $25 \%, \mathrm{MgSO}_{4} \cdot \mathrm{H}_{2} \mathrm{O}$ transforms into $\mathrm{MgSO}_{4} \cdot 4 \mathrm{H}_{2} \mathrm{O}$, with a volume increase of about $10 \mathrm{~cm}^{3}$ when $\mathrm{RH}$ increases.

b) At $35 \% \mathrm{RH}, \mathrm{Mg}\left(\mathrm{NO}_{3}\right)_{2} \cdot 6 \mathrm{H}_{2} \mathrm{O}$ dissolves and $\mathrm{NaCl}$ decreases in volume with a total volume change of around $5 \mathrm{~cm}^{3}$

c) Between $55 \%$ and $60 \% \mathrm{RH}, \mathrm{CaSO}_{4}$ transforms into $\mathrm{CaSO}_{4} \cdot 2 \mathrm{H}_{2} \mathrm{O}, \mathrm{MgSO}_{4} \cdot 4 \mathrm{H}_{2} \mathrm{O}$ becomes $\mathrm{MgSO}_{4} \cdot 6 \mathrm{H}_{2} \mathrm{O}$. The final volume change is $30 \mathrm{~cm}^{3}$, increasing when $\mathrm{RH}$ increases and decreasing when $\mathrm{RH}$ decrease.

d) The most important change takes place between $60 \%$ and $70 \% \mathrm{RH}$. All salts disappear with the exception of $\mathrm{CaSO}_{4} \cdot 2 \mathrm{H}_{2} \mathrm{O}$ that remains stable. Total volume change is almost $60 \mathrm{~cm}^{3}$. Volume decreases when $\mathrm{RH}$ increases and vice versa.

At $30^{\circ} \mathrm{C}$ the following changes are observed when $\mathrm{RH}$ increases:

a) At around $30 \% \mathrm{RH}, \mathrm{Mg}\left(\mathrm{NO}_{3}\right)_{2} \cdot 6 \mathrm{H}_{2} \mathrm{O}$ disappears. $\mathrm{NaCl}$ and $\mathrm{KNO}_{3}$ have a slight decrease of volume.

b) At $35 \% \mathrm{RH}, \mathrm{MgSO}_{4} \cdot \mathrm{H}_{2} \mathrm{O}$ transforms into $\mathrm{MgSO}_{4} \cdot 4 \mathrm{H}_{2} \mathrm{O}$ and $\mathrm{NaNO}_{3}$. The total volume change is $7 \mathrm{~cm}^{3}$.

c) When $\mathrm{RH}$ goes from $55 \%$ and $70 \%$, a decrease of volume of $25 \mathrm{~cm}^{3}$ occurs, all salt disappears except $\mathrm{CaSO}_{4}$

d) At $\mathrm{RH} 75 \%, \mathrm{CaSO}_{4}$ transforms into $\mathrm{CaSO}_{4} \cdot 2 \mathrm{H}_{2} \mathrm{O}$ with an increase of volume of $30 \mathrm{~cm}^{3}$.

As already mentioned these volume values should be taken in a relative sense considering that the maximum precipitated volume is $130 \mathrm{~cm}^{3}$.

As expected the most important volume increases are produced during the relative humidity decrease due to precipitation processes. Reversely, an increase of the relative humidity can induce hydration process of some species leading to volume increase.

Figure 2 shows, for all the selected temperatures (from $0^{\circ} \mathrm{C}$ to $50^{\circ} \mathrm{C}$, every $5^{\circ} \mathrm{C}$ ), the total volume of salt as a function of $\mathrm{RH}$. As a general consideration it can be observed that for the temperatures most commonly found in the Paris area (between $0^{\circ} \mathrm{C}$ and $30^{\circ} \mathrm{C}$ ) salt volume decreases with temperature, mainly between $5^{\circ} \mathrm{C}$ and $20^{\circ} \mathrm{C}$. This model does not take into account thermal expansion of salts due to temperature increases. Differences in thermal expansion between rock forming minerals and salt can be very high [20], so thermal cycles will have a much larger effect on rocks contaminated by salt than on salt-free rocks.

In Figure 2 for each temperature, the conditions corresponding to an increase of volume when RH goes up, have been pointed out. Looking at the graphs it can be seen how these points progressively change with temperature. For example, the increase of volume corresponding to the red arrow moves to higher $\mathrm{RH}$ when temperature increases and is mainly due to $\mathrm{Mg}\left(\mathrm{NO}_{3}\right)_{2} \cdot 6 \mathrm{H}_{2} \mathrm{O}$. Once the different volume increase conditions have been identified, a table of "damage conditions" can be built (Table 2): to do so for each temperature the ranges (beginning and end) of relative humidity corresponding to volume increases are picked up. For each volume increase step (corresponding to an arrow on the figures), the temperature and RH corresponding to the beginning and the end of the volume change are recorded. When plotting these data (RH vs. temperature) one obtains several curves corresponding to the conditions where the total volume of salt increases. For each step two curves are plotted, one corresponding to the lower RH limit and the second one to the upper RH bound. In Figure 3 we plotted as many couples of curves (lower and upper limits) as positive slopes observed ( 3 in this case). The areas between the curves with the same colour correspond to the ranges of temperature and relative humidity with a positive slope in the volume/relative humidity diagrams. Only positive temperatures have been considered, as below $0^{\circ} \mathrm{C}$ other processes producing changes in volume can take place.

Once these graphs constructed and knowing the temperature and relative humidity of one day and the previous one, it can be estimated if some damage will take place or not. The first thing to do is to determine if relative humidity is increasing or decreasing between two consecutive days. If $\mathrm{RH}$ is increasing and the point ( $\mathrm{T}$, $\mathrm{RH}$ ) is inside an area between same colour curves on Figure 3, it can be considered that salt damage takes place. To systematically apply this methodology to meteorological data, the procedure needs to be automated: therefore each curve in Figure 3 has been fitted to mathematical functions (Figure 4).

The same steps have been followed in the case of decreasing relative humidity. Figure 5 is similar to Figure 3 but this time we pointed out the conditions corresponding to salt volume increase when the relative humidity 
decreases. Following the same procedure as explained for increasing relative humidity, the T-RH conditions corresponding to volume increase with decreasing relative humidity have been obtained and fitted to mathematical functions (Figure 6).

Conversely the whole procedure can be done keeping constant relative humidity and varying temperature. The results of total volume as a function of temperature for different values of constant relative humidity between $15 \%$ and $98 \%$ are shown in Figure 7 . It can be observed that at RH below $40 \%$, changes in temperature do not produce a significant volume increase. As in the case of relative humidity, a decrease in temperature is the most important factor for salt precipitation. A temperature increase produces only small precipitation in very specific conditions, as solubility increases with temperature.

Finally combining the information of the different volume/relative humidity and volume/temperature series a " $3 \mathrm{D}$ " representations of the salt volume as a function of meteorological data can be obtained. Figure 8 shows the salt volume function $V=f(T, H R)$ for the selected solution. When estimating salt damage, volume change is more important than total volume values, so the attention should be focused on positive slopes. In Figure 8 the constant volume areas (plateaux) () are more important than the areas where volume is changing, which means that salt damage is concentrated in very specific meteorological conditions, while most of the time changes in temperature and relative humidity do not produce any significant damage.

The proposed methodology does not take into account the material type (stone, brick, concrete, etc), its composition (mineralogical, chemical), its microstructure (porosity, size of the pores, connectivity...) so it should be used to compare the behaviour of the same material with the same salt composition under different meteorological conditions. The most dangerous conditions correspond to relative humidity decreases from $70 \%$ to $55 \%$ and to temperatures going from $0^{\circ} \mathrm{C}$ to $50^{\circ} \mathrm{C}$. These conditions correspond to the "peak" on the left side of Figure 8, with a volume increase of $80 \mathrm{~cm}^{3}$ to $130 \mathrm{~cm}^{3}$. This "peak" is located on the blue area of Figure 6.

\section{Examples to illustrate the methodology}

In order to show how the proposed methodology can be used, two examples are presented.

\subsection{Daily damage estimation at a single location}

First the output of the model discussed above for the mortar salts has been compared to daily meteorological data from the centre of Paris, between 2006 and 2015. For the calculation the constant temperature and variable relative humidity criteria have been chosen for two different reasons:

a) Mathematical expressions for the criteria with constant temperature and varying relative humidity are simpler than those for constant relative humidity and varying temperature.

b) Relative humidity between two consecutive days varies more than temperature. In the case of Paris, mean differences of temperature between two consecutive days divided by the range of temperatures ( $\mathrm{max}-\mathrm{min}$ ) of the selected period (2016-2015) is 0.041 and the same value for relative humidity is 0.097 .

When applying the methodology for each daily data the first step is to check if relative humidity is increasing or decreasing to select which criteria should be applied, either those corresponding to Figure 4 (increasing) or to Figure 6 (decreasing). In the next step, each point is compared to the selected criteria, to check if they are inside the "damage" areas (between two curves of the same colour on Figures 4 or 6 ) for respectively increasing or decreasing relative humidity. To do the calculation a simple Scilab program has been written. The result is a list of the days when salt damage is predicted to take place and their temperature and relative humidity. Figure 9 shows the results obtained for Paris with the salt composition corresponding to the mortar sample.

\subsection{Influence of climate variations at different locations}


This methodology allows one to compare the behaviour of a particular solution composition under different meteorological conditions, or following the evolution of salt damage with climate change. In this paper only the first application has been chosen.

In order to illustrate an example of variations of salt weathering behaviour under different climatic conditions for a unique salt mixture we chose a standard theoretical salt composition of $1 \mathrm{~mol}$ of $\mathrm{NaCl}, 1 \mathrm{~mol}$ of $\mathrm{Na}_{2} \mathrm{SO}_{4}, 1$ mol of $\mathrm{CaSO}_{4} 1 \mathrm{~mol}$ of $\mathrm{MgSO}_{4}$ and $1 \mathrm{~mol}$ of $\mathrm{KNO}_{3}$. The same procedure described before to obtain the functions corresponding to damage conditions has been applied. The graphs showing the damage curves as well as the obtained number of "damage days" for 7 different locations of France corresponding to different climate regions can be seen in Figure 10. All meteorological data come from French meteorological stations of Meteo France (see locations on Figure 10). The selected points are located in different regions: NE, NW, SE, SW and centre of France. A location close to Paris but in a less urban area (Val d'Oise) has been taken for comparison. For these examples, data for a longer period than in the previous case has been used (between 1970 and 2000). For each location the results are presented in two different ways: on the main plot, the temperature and relative humidity conditions of the "damage days" are placed on the HR-T space; and on the inserted plot, the average monthly distribution of the number of damage days is presented. The obtained results should be considered only for comparison of the behaviour of salt weathering produced by a particular salt composition in different locations where the climate is different.

\section{Discussion}

Comparing Figure 8 with Figures 4 and 6 it can be observed that damage areas in Figures 4 and 6 correspond to conditions where volume changes in Figure 8 . This indicates that the presented procedure is a good approach to estimate salt damage by volume increase due to changing meteorological conditions. There are still several aspects that can be improved as for example the fact that the value of volume change is not considered in the calculation, but just if volume change takes place or not. In future developments each damage area will have a weight factor, function of the corresponding increase of volume. During the RH decreasing period damage should have a more important weight compared to that occurring during the $\mathrm{RH}$ increasing period. For example in Figures 2 or 5 , at $5^{\circ} \mathrm{C}$, maximum volume increase is about $30 \mathrm{~cm}^{3}$ when $\mathrm{RH}$ increases, and of about $55 \mathrm{~cm}^{3}$ when $\mathrm{RH}$ decreases.

In Figures 9 and 10, corresponding to the two presented examples, it can be observed that most of the damage is mainly concentrated in the "blue area" and some in the "red areas". The blue areas (decreasing relative humidity) correspond to the precipitation of mirabilite, one of the most dangerous salts for monuments; halite, magnesium sulphate with different hydration degrees as a function of temperature; and magnesium nitrate. The mean volume increase due to mirabilite is about $10 \%$ of the total volume, the same as sodium chloride and magnesium; magnesium nitrate is about $5 \%$. These salts are ones of the most commonly found in weathered materials in building materials.

In Figure 10 only locations $a, e$ and $f$ have a significant number of points in the red areas (increasing relative humidity), corresponding to the hydration of the anhydrite to gypsum. This process produces the most important increase of the total volume compared to other individual salts, about $15 \%$. It can also be observed that seasonality of salt damage is different in different areas. Most of locations have a minimum of damage during the summer time but for location $\mathrm{f}$, damage is maximum at this season. The location corresponding to $d$ point has a quite constant damage all over the year.

Table 3 shows the number of "damage days" per year calculated during the RH increase and decrease periods for the calculation with the "standard composition". The number of days producing damage when relative humidity decreases are much lower than when it increases, which is in accord with general observations.

Selected ranges of temperature and relative humidity used in this paper for the ECOS-RUNSALT calculations are too large and may be reduced to dismiss the number of "damage areas" used to estimate the number of days with salt damage. This can simplify the calculations, even if the Scilab program used takes less than one minute to do the calculations. 
There are some limitations to the method, some of them related to the limitation of the ECOS model itself: limitation in the considered anions and impossibility to introduce gypsum in the global calculations for several environmental conditions. Carbonate and bicarbonate anions are important in the degradation of calcareous stones but also for mortars and other artificial cements materials. Carbonated salt are present in many buildings, for example Eric et al [21] found dolomite and calcite on salt mixture of the Gradac Monastery (Serbia) and Morillas et al [22] found $\mathrm{CO}^{2-}$ on efflorescences analysed by Raman technology on a brick building in Bilbao (Spain).

This study can contribute to the conservation of cultural heritage as it determines the environmental conditions at which damage can take place. The changes of these conditions are more important than the conditions themselves. This fact is largely admitted, but the proposed methodology allows one to quantify this damage. Knowing the actual meteorological condition and how climate is supposed to change in the next years, the proposed methodology can help decision takers in the choice of cultural heritage conservation strategy.

As for any model some simplifications have been done. Weathering is the results of a combination of several parameters and processes that are very complex (maybe impossible) to model simultaneously. The present model only takes into account volume changes due to precipitation/dissolution and hydration/dehydration process. Thermal expansion, chemical alteration, etc. are not considered.

In a previous work, salt weathering evolution with climate has been estimated by single salts considered independently [15]. In contrast this model allows one to consider several salts acting at the same time, even if there is not a unique salt composition for all the buildings and materials. In a single building salt composition can change with orientation, height, location, etc. The presented results should be considered only as comparisons between different climatic conditions or between past and future.

\section{Conclusions}

This paper presents an innovative procedure to estimate salt damage from meteorological data. In previous work salt weathering has been estimated by the individual action of single salt composition. The presented procedure takes into account that salts in monuments are usually present as mixtures and that the nature and proportions of precipitated salts will depend on the environmental condition and concentration. The proposed methodology used the ECOS-RUNSALT model to estimate salt weathering from temperature and relative humidity for a complex salt mixture. The composition of the salt mixture can be chosen in function of the studied object (building, statue, etc.). If salt determination has been done, the obtained composition can be used to know what will be the behaviour of this object in another environment or in the future with changing climatic conditions. Another important application of the proposed methodology is to help in the choice of optimal conditions to be imposed (if possible) to assure the best conservation of the cultural heritage.

\section{Acknowledgements}

I would like to thank MeteoFrance for providing the meteorological data used in this paper. I would like also to thank Christian David for his thorough reading and help in the writing of this paper. Finally I thank an anonymous reviewer for her/his help in correcting data errors concerning RUNSALT calculations.

\section{References}

[1] A. Arnold, Determination of salts from monuments, Studies in Conservation 29 (1984), 129- 138

[2] A. Goudie, H.A. Viles, Nature of salt involved in salt weathering and sources of moisture, In Salt Weathering Hazards (1997), 256 p, Wiley Ed.

[3] D.E. Searle, D.J. Mitchel, The effect of coal and diesel particulates on the weathering loss of Portland Limestone in an urban environment, Science of The Total Environment 370 (2006), 207-23 . 
[4] D. West, Brard's test into the $21^{\text {st }}$ century: Sodium sulfate soundness testing of dimension stone. In Dimension Stone and Other Sandstone Geomaterials, G.H. McNally and B.J. Franklin eds. Geological Society of Australia - Environmental, Engineering and Hydrology Specialist Group, Monograph No. 5 (1824), pp.138-148. (eds), Sandstone City: Sydney's

[5] A.S. Goudi, H.A. Viles. Weathering precesses and forms, In The History of the Study of Landforms of the Developement of Geomorphology, vol 4 Quaternary and Recent Processes and Forms (1890-1965) and the Mid-centry Revolutions. (2008) 129-164, Geological Society, Burt, Chorley, Brunsden, Cox and Goidue Eds.

[6) C. Rodriguez-Navarro, E. Doehne, E. Sebastian, How does sodium sulfate crystallize? Implications for the decay and testiong of building materials. Cement and Concrete Research 30 (2000) 1527-1534.

[7] A. La Iglesia, V. Gonzalez b, V. Lopez-Acevedo, C. Viedma, Salt crystallization in porous construction materials I Estimation of crystallization pressure, Journal of Crystal Growth 177 (1997) 111-118

[8] N. Shahidzadeh-Bonn, J. Desarnaud, F. Bertrand, X. Château, D. Bonn. Damage in porous media due to salt crystallization, Physical ReviewE, 81 (2010), 066110.

[9] D. Benavente, P. Brimblecombe, C. M. Grossi. Thermodynamic calculations for the salt crystallisation damage in porous built heritage using PHREEQC, Environmental Earth Sciences74 (2015) 2297-2313

[10] C. Price, An Expert Chemical Model for Determining the Environmental Conditions Needed to Prevent Salt Damage in Porous Materials. (2010) ISBN: 1873132522, $136 \mathrm{p}$

[11] D. Bionda, 2002-2005. RUNSALT computer program. http://science.sdf-eu.org/runsalt/.

[12] M. Steiger, A. Heritage. Modelling the crystallization behavior of mixed salt systems: input data requirements. In 12th International Congress on the Deterioration and Conservation of Stone; 22-26 October

[13] C. Cardell, D. Benavente, J. Rodriguez-Gordillo, Weathering of limestone building material by mixed sulfate solutions. Characterization of stone microstructure, reaction products and decay forms, Materials characterization 59 (2008) 1371-1385

[14] B. Menéndez, Salt weathering of three French calcareous stones: incidence of salt brine composition and environmental conditions. In MonuBasin9. Ankara, 2014.

[15] C.M. Grossi, P. Brimblecombe, B. Menendez, D. Benavente, I. Harris, M. Deque, Climatology of salt transitions and implications for stone weathering. Science of the Total Environment, 409 (2011), 2577-2585

[16] D. Benavente, P. Brimblecombe, C.M. Grossi, Salt weathering and climate change. M.P. Colombini, L. Tasso (Eds.), New trends in analytical, environmental and cultural heritage chemistry, Transworld Research Network (2008), pp. 277-286 Chapter 10

[17] B. Menendez, Salt climatology applied to built Cultural Heritage. In « Cultural heritage from climate change to global change ». Published by Centro Universitario Europeo per i Beni Culturali di Ravello Edited by RogerAlexandre Lefèvre and Cristina Sabbioni. Sous presse (2016)

[18] P. Lopez-Arce, M. Tagnit-Hammou, B. Menendez; J.D. Mertz, A. Kaci, Durability of stone-repair mortars used in historic buildings from Paris. Materials and Structures (2016) DOI 10.1617/s11527-016-0846-0

[19] K. Heinrichs, R. Azzam, Quantitative Analysis of Salt Crystallization-Dissolution Processes on Rock-Cut Monuments in Petra/Jordan, Engineering Geology for Society \& Territory 8 (20151) 507-510

[20] E.M. Winkler, Stone in architecture. 3rded (1994) Berlin-Heidelberg New York, Springer, 313p.

[21] S. Erić, V. Matović, , A. Kremenović, , P. Colomban, D. Srećković Batoćanin, M. Nešković, A. Jelikić, The origin of $\mathrm{Mg}$ sulphate and other salts formed on pure calcium carbonate substrate - Tufa stone blocks built into the Gradac Monastery, Serbia, Construction and Building Materials 98 (2015) 25-34 
[22] H. Morillas, M. Maguregui, J. Trebolazabala, J.M. Madariaga, Nature and origin of white efflorescence on bricks, artificial stones, and joint mortars of modern houses evaluated by portable Raman spectroscopy and laboratory analyses, Spectrochimica Acta Part A: Molecular and Biomolecular Spectroscopy, 136, Part B, (2015, 1195-1203 


\begin{tabular}{|c|c|c|c|c|c|c|c|c|c|}
\hline \multirow[t]{2}{*}{ Anion } & \multirow[t]{2}{*}{$\begin{array}{l}\text { Original } \\
\text { (ppm) }\end{array}$} & \multirow[t]{2}{*}{$\begin{array}{l}\text { Corrected } \\
\mathrm{Ca}^{2+}(\mathrm{g})\end{array}$} & \multicolumn{2}{|c|}{$\begin{array}{c}\text { Corrected gypsum } \\
\text { (g) }\end{array}$} & \multirow[t]{2}{*}{ Cation } & \multirow[t]{2}{*}{$\begin{array}{c}\text { Original } \\
\text { (ppm) }\end{array}$} & \multirow[t]{2}{*}{$\begin{array}{c}\text { Corrected } \\
\mathrm{Ca}^{2+}(\mathrm{g})\end{array}$} & \multicolumn{2}{|c|}{$\begin{array}{c}\text { Corrected gypsum } \\
(\mathrm{g})\end{array}$} \\
\hline & & & $\begin{array}{l}\text { without } \\
\text { gypsum }\end{array}$ & gypsum & & & & $\begin{array}{l}\text { without } \\
\text { gypsum }\end{array}$ & gypsum \\
\hline $\mathrm{Cl}^{-}$ & 29.7 & 29.7 & 29.7 & 0 & $\mathrm{Na}^{+}$ & 22.2 & 22.2 & 22.2 & 0 \\
\hline $\mathrm{SO}_{4}{ }^{2-}$ & 105 & 105 & 16.5 & 88.5 & $\mathrm{~K}^{+}$ & 8.6 & 8.6 & 8.6 & 0 \\
\hline \multirow[t]{2}{*}{$\mathrm{NO}^{3-}$} & 25.3 & 25.3 & 25.3 & 0 & $\mathrm{Mg}^{2+}$ & 4.9 & 4.9 & 4.9 & 0 \\
\hline & & & & & $\mathrm{Ca}^{2+}$ & 96.9 & 36.9 & 0 & 36.9 \\
\hline
\end{tabular}

Table 1. Solution ionic compositions obtained from dissolution of salt contained in a mortar sample of the "Préfecture de Police" building in Paris. Original: result of ion chromatography in ppm. Corrected $\mathrm{Ca}^{2+}$ : after correction to equilibrate charges ( $\mathrm{Ca}^{2+}$ excess has been taken off). Corrected gypsum: gypsum ions have been extracted $\left(\mathrm{Ca}^{2+}\right.$ and $\left.\mathrm{SO}_{4}{ }^{2-}\right)$, left column shows values used for calculation of other salts volume, and right column those used for calculation of gypsum volume in a separate run. Corrected values are expressed in $\mathrm{g}$ of element by $10 \mathrm{~kg}$ of mortar sample. Adapted from [18]. 


\begin{tabular}{|c|c|c|c|c|c|c|}
\hline \multicolumn{7}{|c|}{ Decreasing Relative humidity } \\
\hline \multirow{2}{*}{$\begin{array}{c}\text { Temperature } \\
\left({ }^{\circ} \mathrm{C}\right)\end{array}$} & \multicolumn{6}{|c|}{ Relative humidity (\%) - Low and high limits of slopes } \\
\hline & \multicolumn{2}{|c|}{ Brown arrow } & \multicolumn{2}{|c|}{ Blue arrow } & \multicolumn{2}{|c|}{ Grey arrow } \\
\hline 0 & 38 & 40 & 63 & 71 & 84 & 93 \\
\hline 5 & 36 & 39 & 61 & 68 & 81 & 86 \\
\hline 10 & 35 & 38 & 60 & 68 & 91 & 96 \\
\hline 15 & 35 & 37 & 60 & 70 & & \\
\hline 20 & 33 & 35 & 58 & 68 & & \\
\hline 25 & 33 & 35 & 55 & 68 & & \\
\hline 30 & 31 & 33 & 54 & 70 & & \\
\hline 35 & 30 & 32 & 52 & 70 & & \\
\hline 40 & 28 & 30 & 48 & 70 & & \\
\hline 45 & 28 & 30 & 46 & 70 & & \\
\hline 50 & 27 & 29 & 40 & 70 & & \\
\hline & & & & & & \\
\hline \multicolumn{7}{|c|}{ Increasing Relative humidity } \\
\hline & \multicolumn{2}{|c|}{ Green arrow } & \multicolumn{2}{|c|}{ Red arrow } & \multicolumn{2}{|c|}{ Purple arrow } \\
\hline 0 & 16 & 18 & 41 & 43 & 46 & 50 \\
\hline 5 & 18 & 20 & 46 & 48 & 49 & 52 \\
\hline 10 & 21 & 23 & 51 & 55 & & \\
\hline 15 & 23 & 25 & 56 & 60 & & \\
\hline 20 & 26 & 28 & 63 & 65 & & \\
\hline 25 & 30 & 32 & 68 & 71 & & \\
\hline 30 & 33 & 35 & 74 & 76 & & \\
\hline 35 & 38 & 40 & 81 & 83 & & \\
\hline 40 & 41 & 43 & 89 & 93 & & \\
\hline 45 & 45 & 47 & & & & \\
\hline 50 & & & & & & \\
\hline & & & & & & \\
\hline
\end{tabular}

Table 2. Temperature and relative humidity points corresponding to beginning and end of volume increase ranges obtained from Figures 2 and 5 for the salt mixture composition of the mortar sample. These values have been used to construct Figure 9 


\begin{tabular}{|l|c|c|}
\hline Department & $\begin{array}{c}\text { \# days damage RH } \\
\text { increasing/year }\end{array}$ & $\begin{array}{c}\text { \# days damage RH } \\
\text { decreasing/year }\end{array}$ \\
\hline Paris & 15.1 & 22.5 \\
\hline Haut Rhin & 7.8 & 255.8 \\
\hline Hérault & 13.0 & 186.3 \\
\hline Indre & 5.4 & 247.6 \\
\hline Manche & 0.7 & 50.0 \\
\hline Pyrénées Atlantiques & 6.3 & 256.7 \\
\hline Val d'Oise & 3.2 & 217.6 \\
\hline
\end{tabular}

Table 3. Distribution of the damage occurring days when relative humidity increases and decreases between two consecutive days. 
$0^{\circ} \mathrm{C}$

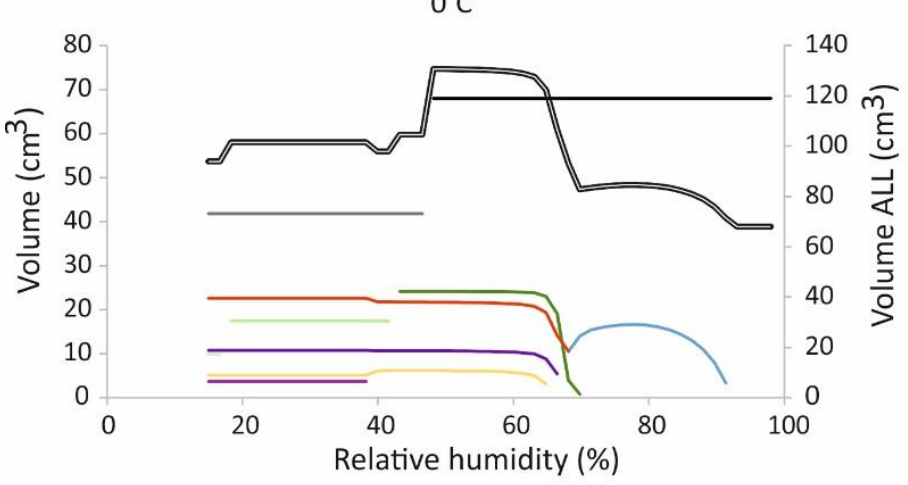

$15^{\circ} \mathrm{C}$
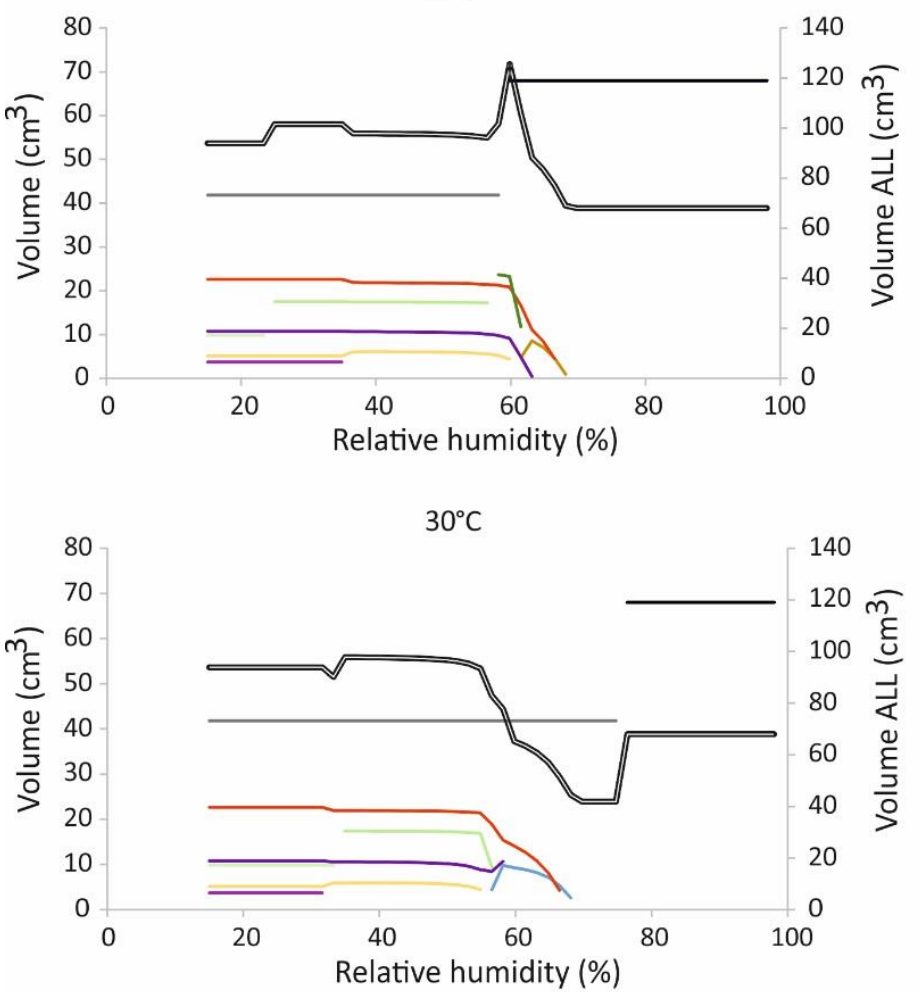

$45^{\circ} \mathrm{C}$

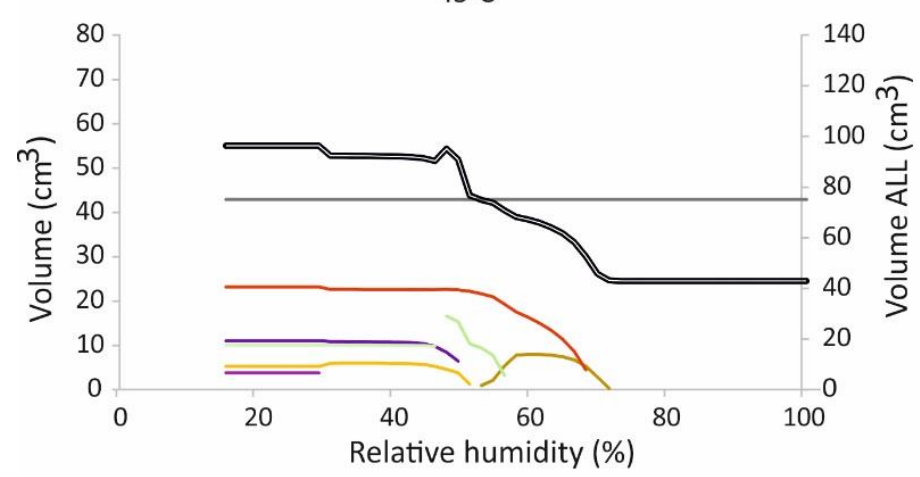

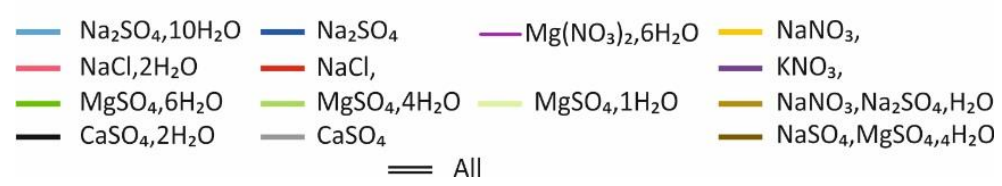

Figure 1. ECOS-RUNSALT simulations at different constant temperatures and variable relative humidity. Every salt evolution is shown with a different colour. The double black line corresponds to the addition of all salt volumes (right vertical scale). 

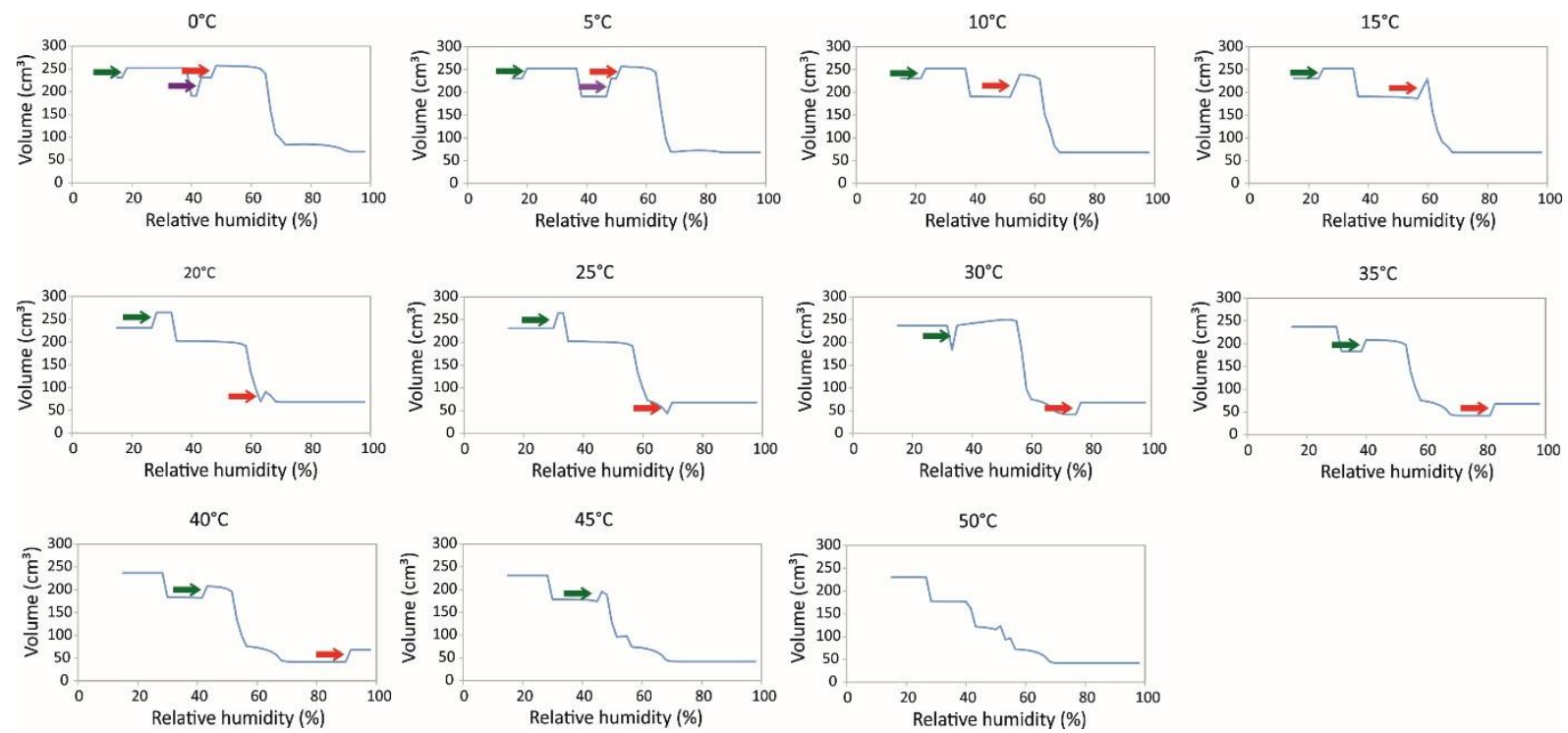

Figure 2. Evolution of total salt volume with relative humidity at different constant temperatures. Arrows indicate the conditions where salt volume increases when relative humidity increases. 


\section{Increasing relative humidity}

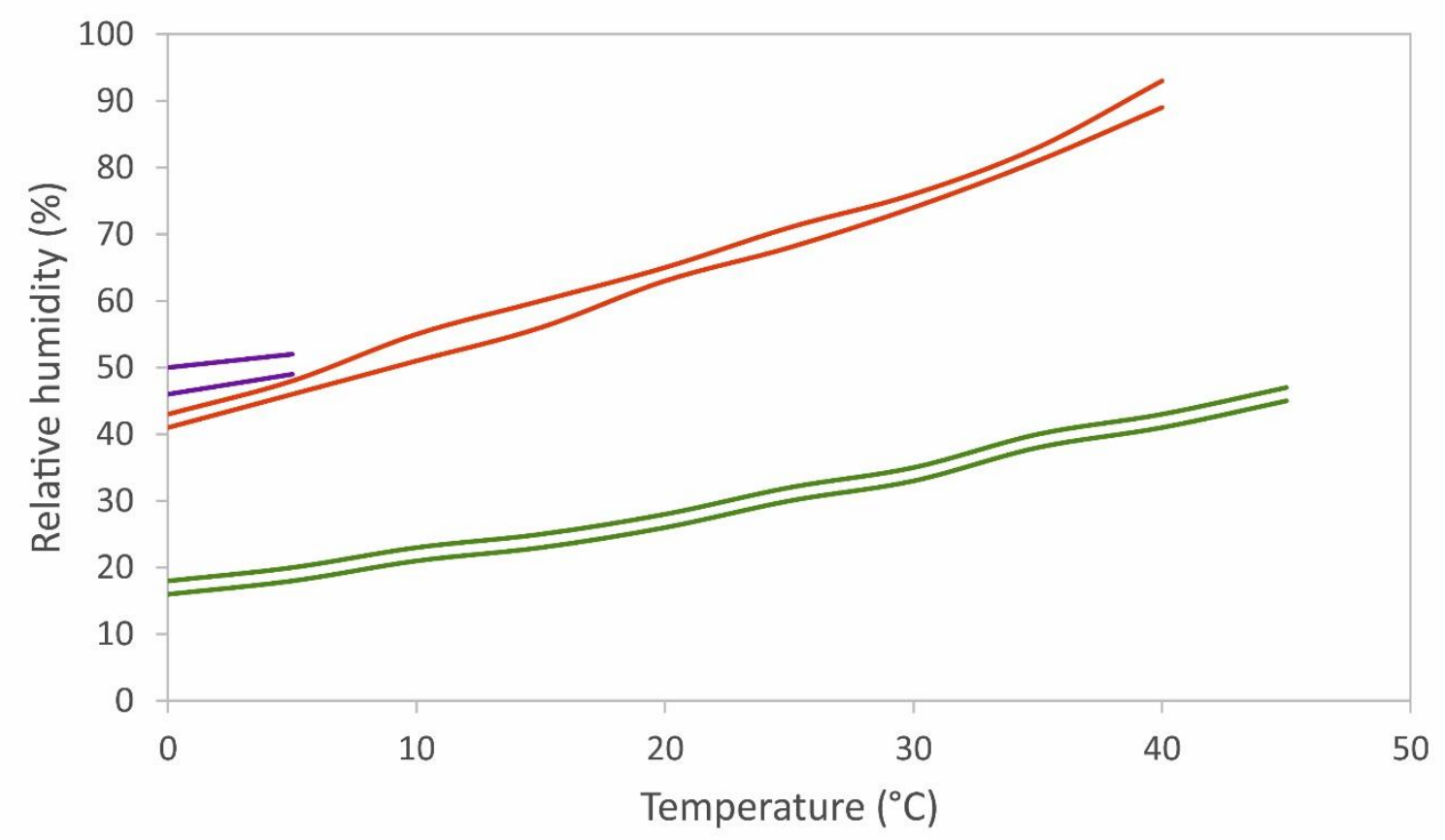

Figure 3. Different areas (temperature /relative humidity) conditions where damage due to the increase of salt volume takes places. 
Increasing relative humidity

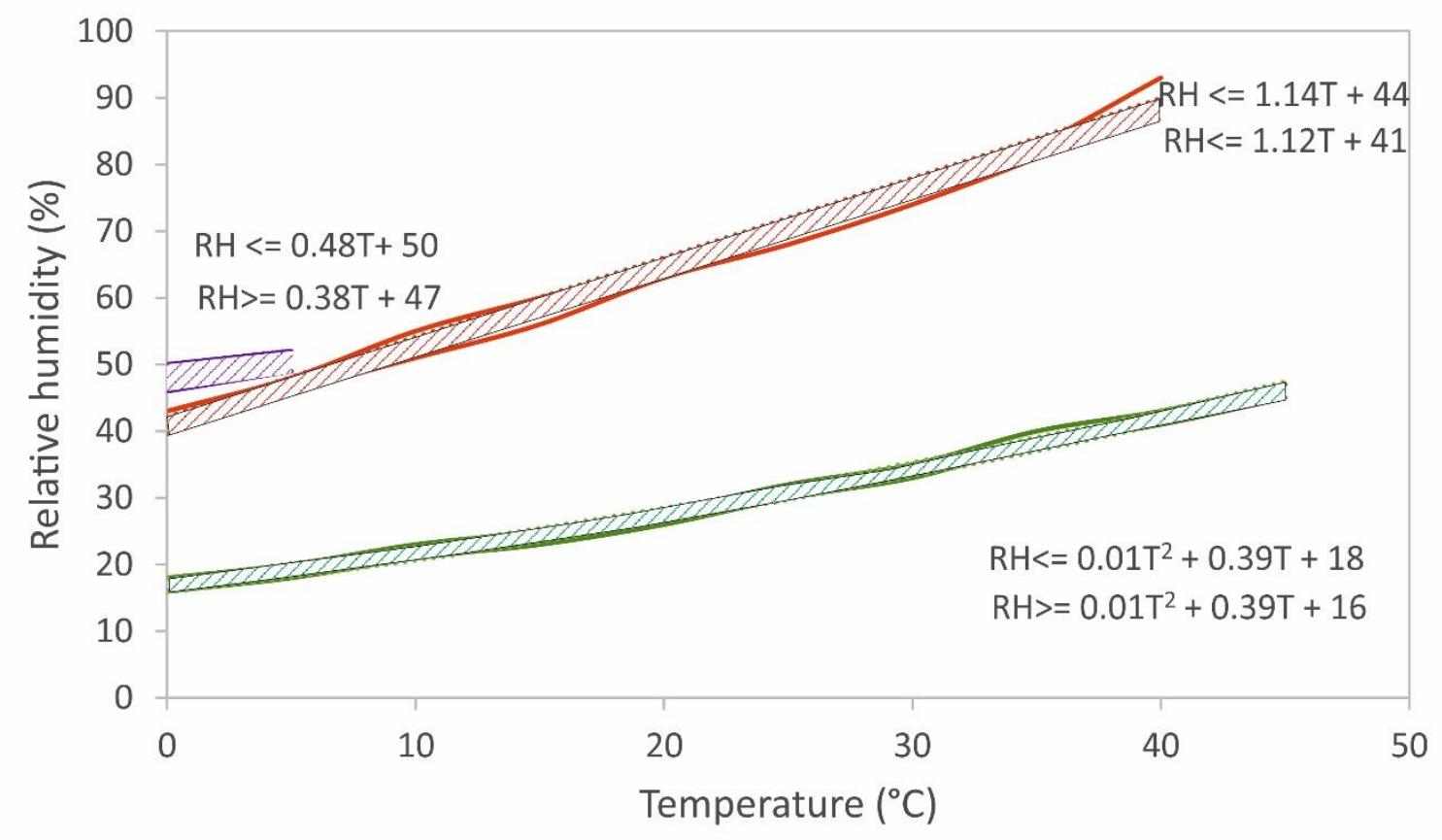

Figure 4. Different areas (temperature /relative humidity) conditions where damage due to the increase of salt volume takes places when relative humidity increases with the mathematical functions describing their limits. 

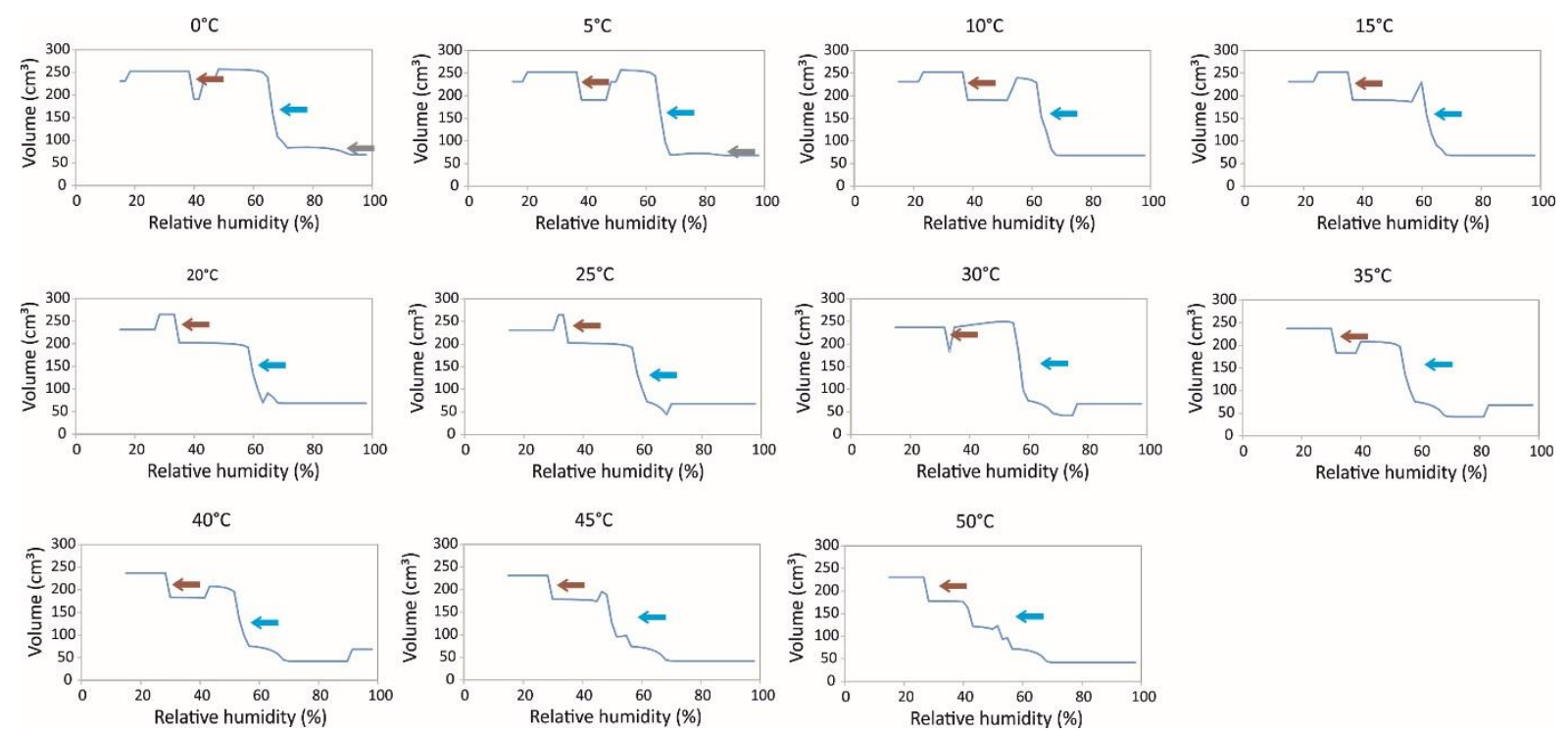

Figure 5. Evolution of total salt volume with relative humidity at different constant temperatures. Arrows indicate the conditions where salt volume increases when relative humidity decreases. 


\section{Decreasing relative humidity}

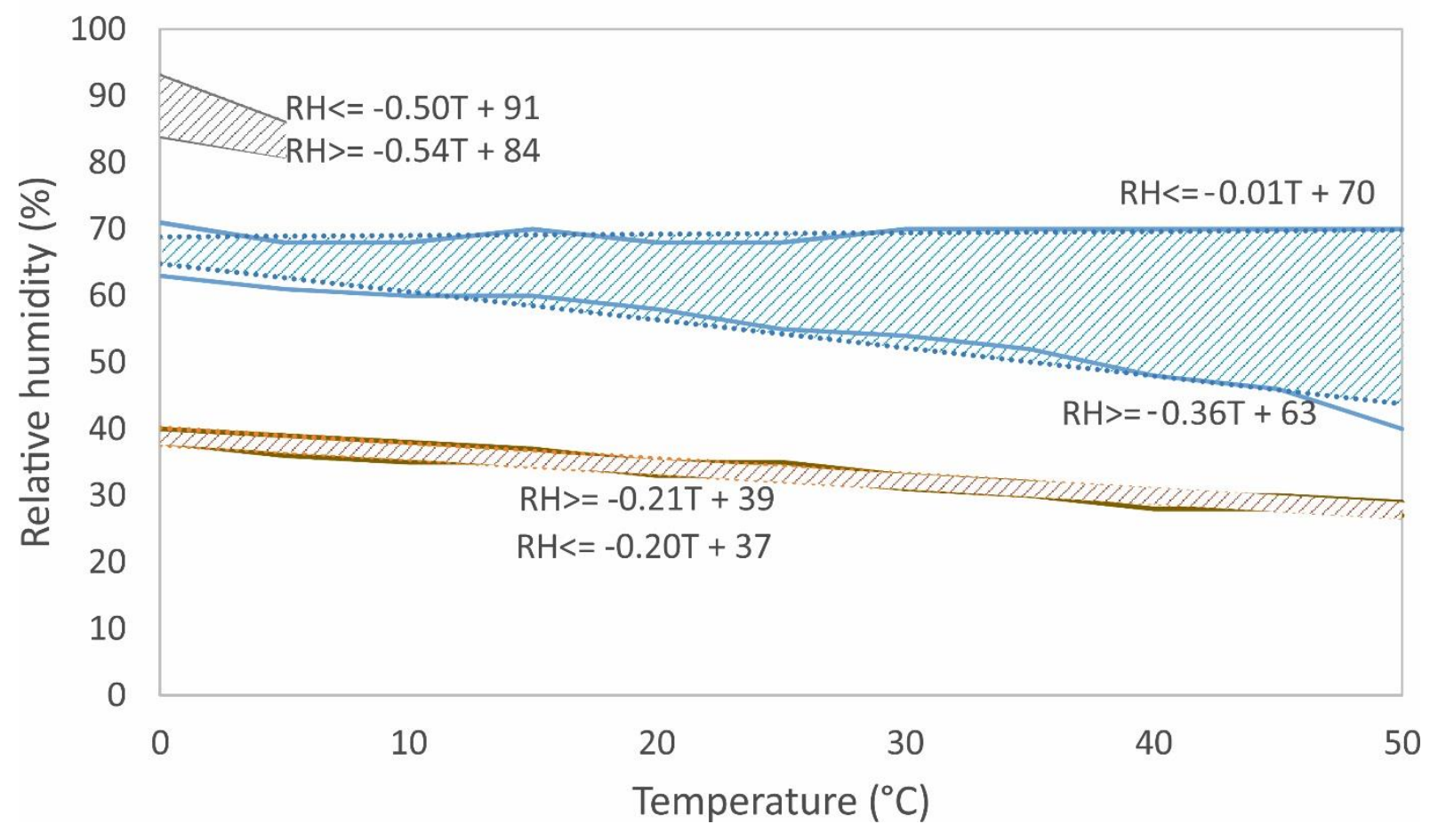

Figure 6. Different areas (temperature /relative humidity) conditions where damage due to the increase of salt volume takes places when relative humidity decreases with the mathematical functions describing their limits. 
$25 \%$

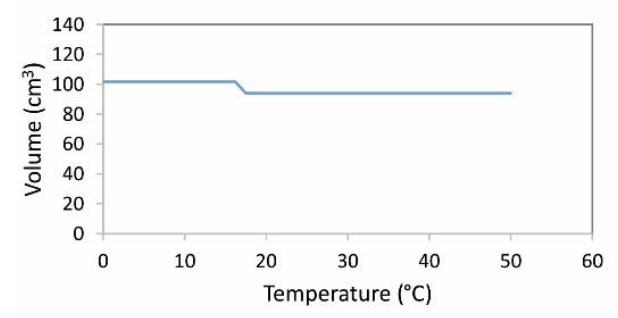

$45 \%$

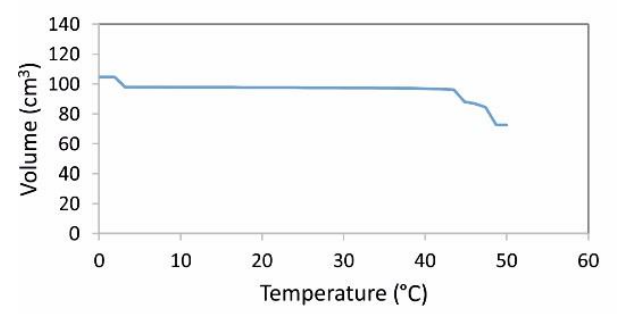

$65 \%$

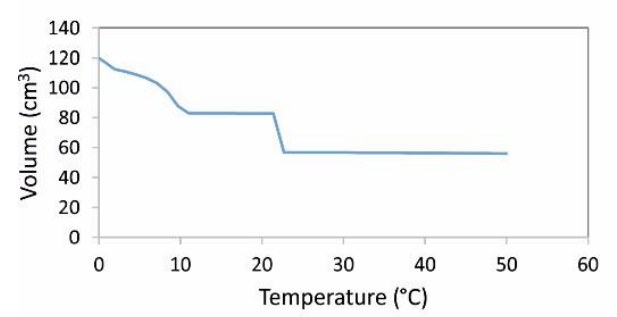

$85 \%$

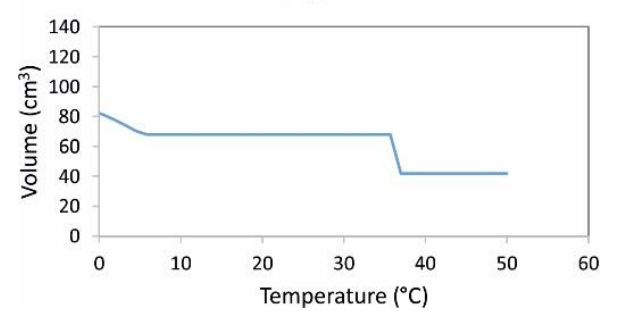

$35 \%$

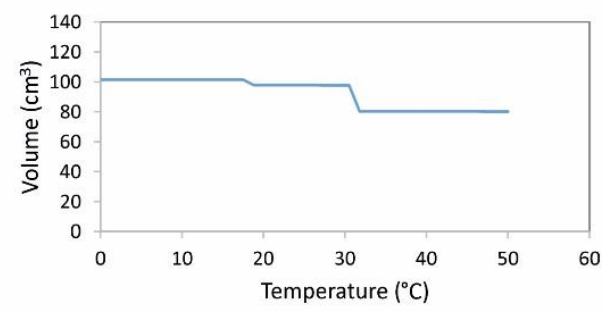

$55 \%$

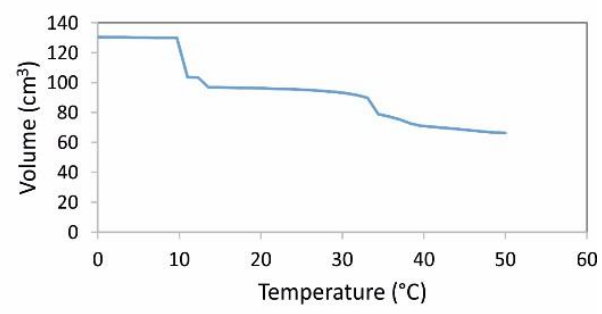

$75 \%$

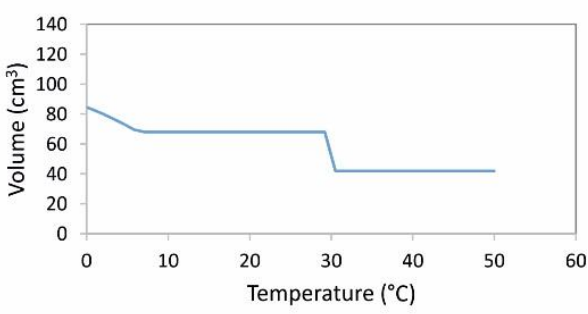

$95 \%$

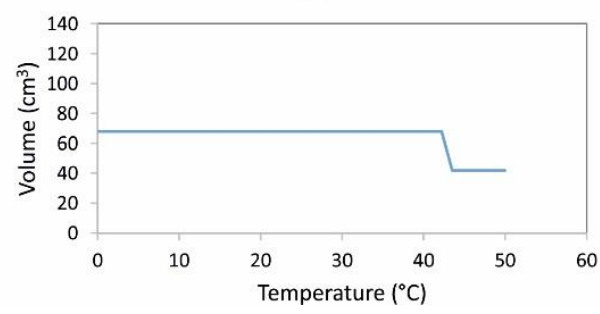

Figure 7. Salt volume variation as a function of temperature at different constant relative humidities. 


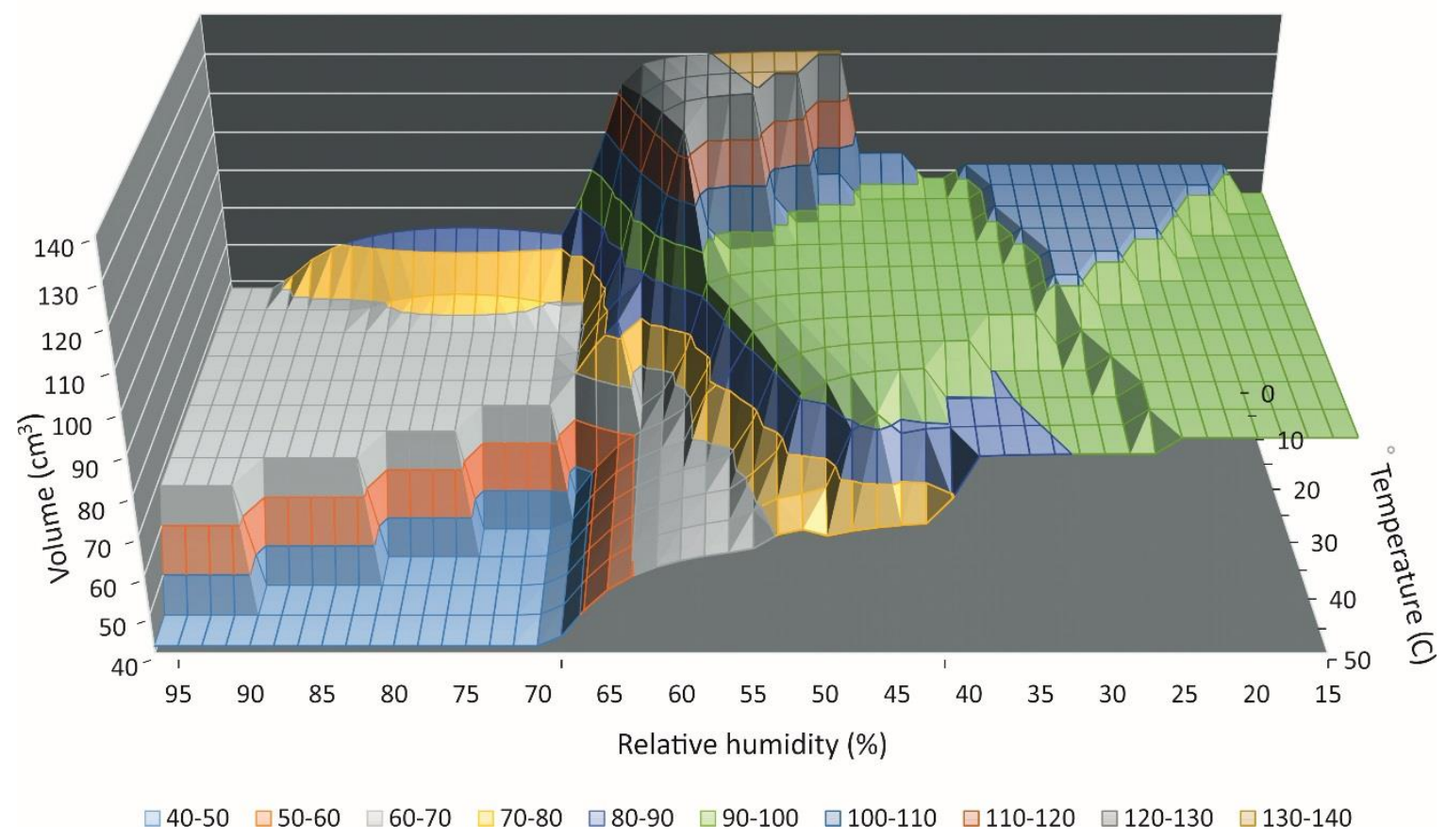

Figure 8. Salt volume as a function of temperature and relative humidity for the selected salt mixture.

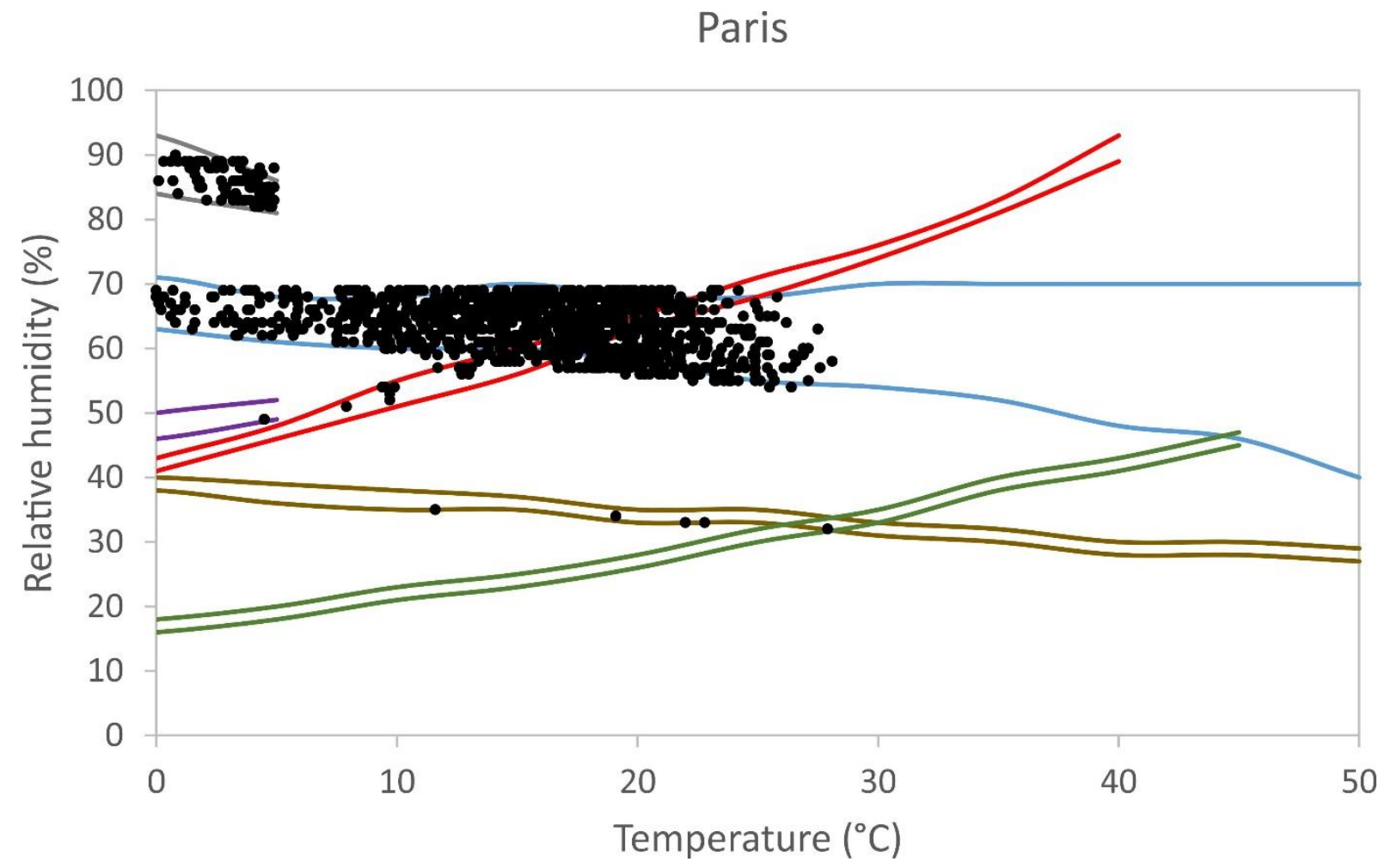

Figure 9. Results obtained using the model for Paris Climate data with the salt composition of the mortar sample. 

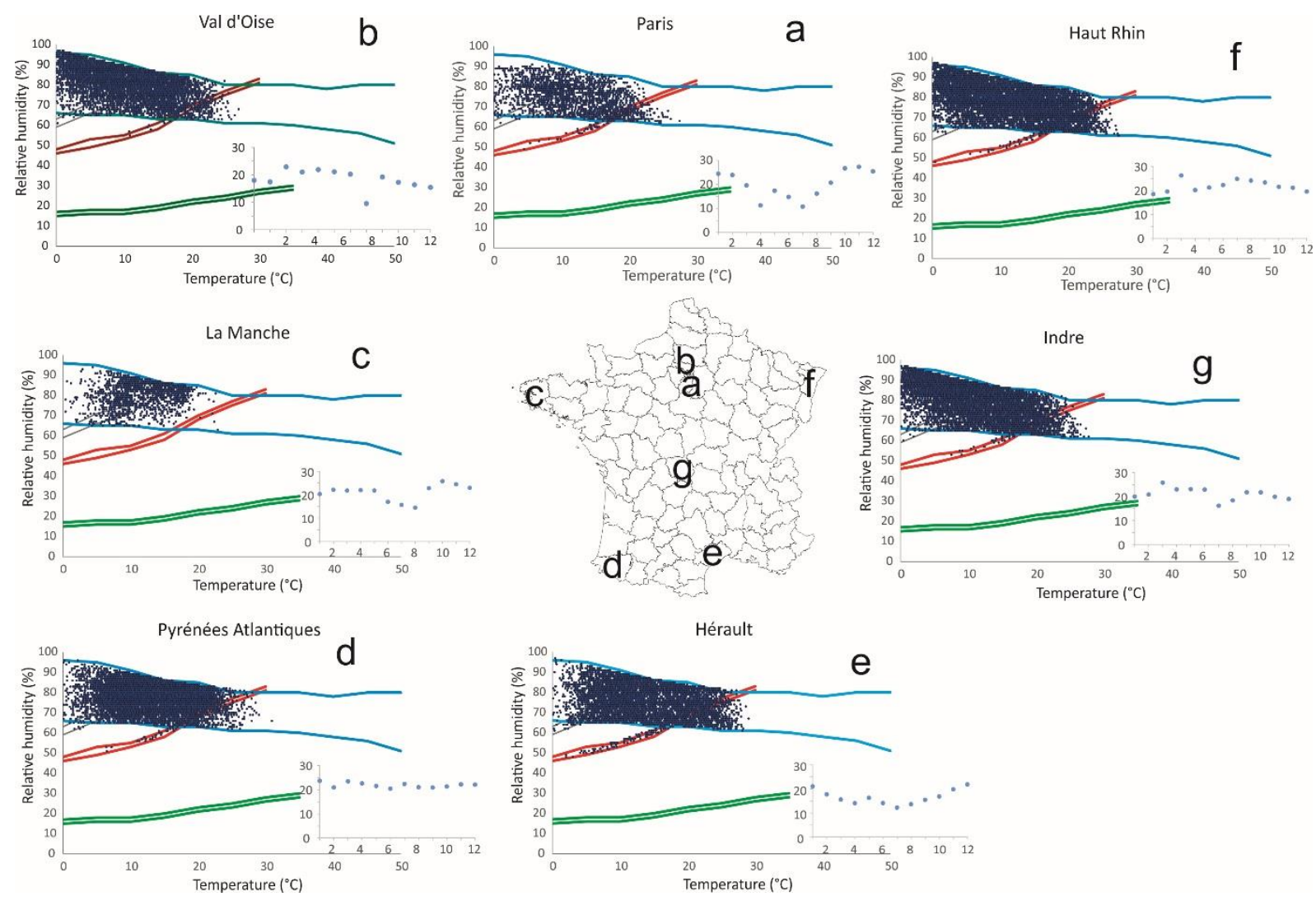

Figure 10. Results of the damage simulations for 6 different locations in France. Main plots: meteorological condition of day causing damage. Inserted plots: average monthly distribution of the number of days producing damage. 